\title{
Improved thermal energy storage for nearly zero energy buildings with PCM integration
}

\author{
Rok Stropnik*, Rok Koželj, Eva Zavrl, Uroš Stritih \\ University of Ljubljana, Faculty of Mechanical Engineering, Aškerčeva 6, 1000 Ljubljana, Slovenia \\ *Corresponding author: rok.stropnik@,fs.uni-lj.si
}

\begin{abstract}
Prudent and efficient utilization of renewable energy sources is needed in order to achieve clean energy transition. Since energy use in buildings represents around $40 \%$ of total energy use in European Union the reduction of energy use in this sector is most definitely needed. One of the great challenges in this sector represents retrofit of residential buildings where $3 / 4$ of buildings in Europe are residential. To reduce energy consumption and increase the use of renewables in existing residential buildings to achieve nearly zero energy buildings (nZEB) a holistic approach of retrofit with interconnected technological system is needed. In the first part of this paper the $n Z E B$ and thermal energy storage are introduced for further implementation of the phase change material (PCM) into storage tank. Furthermore energy toolkit based on the synergetic interaction between technologies integrated in the system for holistic retrofit of residential buildings, which is under development within HEART project (HORIZON 2020), is presented. In this project step towards self-sufficient heating and cooling of building is made with increase in on-site consumption of self-produced energy from solar energy and interconnection between PV, electrical storage, heat pump, thermal energy storage, fan coil heat pump, cloud based decision support and building energy management system. With such a smart energy system the almost zero-energy buildings will be possible to decrease energy use in residential sector. Improvement of sensible thermal energy storage with implemented cylindrical modules filled with PCM is investigated experimentally. The results from experiment show that thermal energy storage unit with integrated modules filled with PCM can supply desired level of water temperature for longer period of time. The advantage of PCM in thermal energy storage is in applications that needs narrow temperature range of supplying and storing thermal energy what is the subject matter of consideration in the case of HEART project.
\end{abstract}

Keywords: Thermal energy storage, PCM, nZEB, experimental analysis, HEART toolkit

\section{Introduction}

Prudent and efficient utilization of renewable energy sources is needed in order to meet demands from European directive on the energy performance of buildings (EPBD) and to comply with Paris agreement for global clean energy transition. To reduce final energy use in newly constructed buildings is one thing but it represents a great challenge in existing ones. Higher energy consumption, limited quantities of fossil fuels and bigger pollution caused because of its use led to several European directives which commits to efficient, prudent, rational and sustainable utilization of energy use what would allow European Union to comply with newly agreed Paris agreement to reduce at least $40 \%$ of greenhouse gas emissions below 1990 levels until 2030 what is in line to secure global temperature increase below $2 \mathrm{~K}$, (European Commission, 2016).

Ever since the researchers on renewable energy field have been encouraged with EPBD improvement on utilizing renewable energy sources has been reached. Now they are facing with new challenge how to further lower environmental impact and reach almost zero energy buildings (nZEB) with RES utilization.

However the challenge in utilizing RES is in its time unsteadiness when mismatch between production and demand occurs. Thermal energy storage will play one of the key roles to achieve nZEB with utilization of RES. To achieve this target, it is first necessary to reduce the energy demand of the building through the implementation of effective passive retrofitting initiatives, such as upgrading the envelope, glazing and 
shading systems, using natural ventilation, passive thermal energy storage followed retrofitting and application of advanced active systems, (Fiorentini et al., 2015). With thermal energy storage integration into nZEB energy system and RES integration is possible to lower mismatch between production from RES and demand for heating or cooling of buildings. Other researchers study different energy systems with sensible heat storage for nZEB but in the last years latent heat storage gain a lot of interest for implementation within residential sector, (Good et al., 2015) .Thus thermal energy storage allows efficient utilization of RES where among different materials of storing thermal energy, phase change materials (PCM) have perspective of having higher energy density, (Nchelatebe and Haghighat, 2013). Especially in low energy buildings with a high share of passive heating, this can significantly improve the utilization of solar energy for heating what is one of the key roles for nZEB, (Arkar and Medved, 2015).

A number of researches have already been carried out in this field and many prototypes have been developed. A lot has been done within IEA Solar Heating and Cooling Programme under Task 32 Advanced storage concepts, (J. M. Schultz et al., 2007). During this task research in Lleida University, Spain, has been performed where bottles with PCM with graphite matrix for the enhancement of the heat conduction were tested. In the Applied University of West-Switzerland a parametric study for the use of PCM in heat storages for solar combi systems was performed. The Institute of Thermal Engineering at Graz University of technology preformed tests and simulations of PCMs in heat stores and of PCM - slurries for conventional boilers to reduce cycling time.

Mehling et al. (MEHLING et al., 2003) studied the impact of the integration of PCM modules at the top of the water storage tank and found that this improves storage density by 20 to $45 \%$, allowing reheating of the transition layer after partial unloading and thus reducing heat losses.

Auzeby et al. (Auzeby et al., 2017) described the overheating issue in residential buildings during summer, where no air-conditioning has been installed. PCMs were considered as a useful passive method, which absorbed the excessive heat when a room was hot and released the stored heat when the room was cold. According to the results, PCMs have the potential to reduce the overheating problem in residential buildings.

To achieve almost zero-energy buildings in future thermal energy storage (TES) technologies are mandatory. The main advantages of using TES in nZEB buildings are: increase in overall efficiency and better reliability of storage, better economics, reductions in investment and running costs and lower environmental impact, (Sarbu and Sebarchievici, 2018).

The main focus of this paper is to present implementation and possible use of latent thermal energy storage in residential sector to achieve almost zero energy buildings and how should be this technologies interconnected within a smart energy system. In the first part of this paper the nZEB and thermal energy storage are introduced for further implementation of the PCM into storage tank. Furthermore energy toolkit based on the synergetic interaction between technologies integrated in the buildings for holistic retrofit of residential buildings is presented. The last part of this paper the improvement of sensible thermal energy storage tank with implemented cylindrical modules filled with PCM is investigated experimentally and explained more in detail. Finally the main conclusions are presented and the paper is concluded with acknowledgments, references.

\section{Nearly zero energy building - nZEB}

The definition according to EU commission for nZEB are: Very high energy performance building with a very low amount of energy required covered to a very significant extent by energy from on-site or nearby renewable sources, (D'Agostino and Mazzarella, 2019). The performance level of nearly zero energy buildings (nZEB) is a subject of national decision and definition for uniformed EPBD recast implementation are, (Kurnitski, 2013):

$>$ Net zero energy building (NZEB): non-renewable primary energy consumption of $0 \mathrm{kWh} /\left(\mathrm{m}^{2} \mathrm{a}\right)$.

$>$ Nearly zero energy building (nZEB): technically and reasonably achievable national energy use of $>0 \mathrm{kWh} /\left(\mathrm{m}^{2} \mathrm{a}\right)$ but no more than a national limit value of non-renewable primary energy, achieved with a combination of best practice energy efficiency measures and renewable energy technologies, which may or may not be cost optimal. 


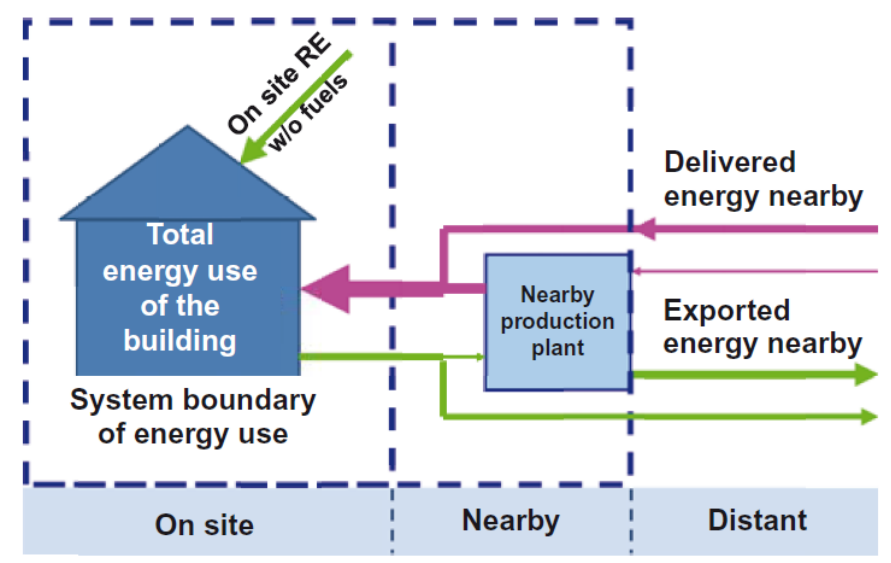

Figure 1: System Boundary to assess delivered energy for nZEB, (Kurnitski et al., 2012)

\section{Thermal Energy storage}

Energy storage system can be divided into 4 main categories: Mechanical energy storage, Chemical Energy Storage, Biological Energy Storage, Magnetic Energy Storage and Thermal Energy Storage. Thermal energy storage is divided into three categories: Sensible, Latent and Chemical Heat Storage, (Gil et al., 2010). In following chapter the focus is on sensible (most common) and latent heat storage with working principle for potential use in almost zero energy buildings.

\subsection{Sensible heat storage}

Sensible heat storage is by far the most commonly used principle of thermal energy storage. Heat is stored by changing the temperature of storage medium, for example water, sand, earth etc. The principle of heat storage in this method is based on changing the temperature of the storage media without phase change. The amount of stored heat is proportional to the temperature rise $(T)$, the specific heat capacity $\left(C_{p}\right)$ and the mass $(\mathrm{m})$ of the medium, as shown in Equation (1). The rise in temperature is a consequence of increased kinetic energy of the molecules. This change in internal energy of storage medium can be sensed by temperature sensors and consequently is called sensible heat.

$\Delta Q_{S}=m \cdot c_{p} \cdot \Delta T$

\subsection{Latent heat storage}

In case of latent heat storage heat is stored through phase change of storage medium. During phase change of medium heat can be released at nearly constant temperature. These offers storage densities 5 to 15 times greater compared to sensible storages. Materials used in latent heat storages are known as phase change materials (PCMs). The most common change of phase used in the system is solid - liquid, but there are also systems that use solid - gas, liquid - gas and solid - solid change of phase. The amount of stored heat is proportional to the mass of the medium $(\mathrm{m})$ and the change of specific enthalpy $(\mathrm{h})$ between the phases, as shown in Equation (2).

$\Delta Q_{L}=m \cdot \Delta h$

\subsection{Working principle}

The Figure 2 shows a comparison between sensible and latent principle of storing heat. Below the temperature of phase change both materials heat up evenly when heat is supplied, assuming they have the same specific heat capacity. This increases kinetic energy of molecules or the oscillation of molecules. When the temperature of the phase change is reached, the temperature of the medium for latent heat storage does not change when further heat is supplied. The heat input is reflected as an increased potential energy of the molecules, while the kinetic energy remains the same. After the phase change is completed, the kinetic energy of the molecules increases again with further heat supply. 


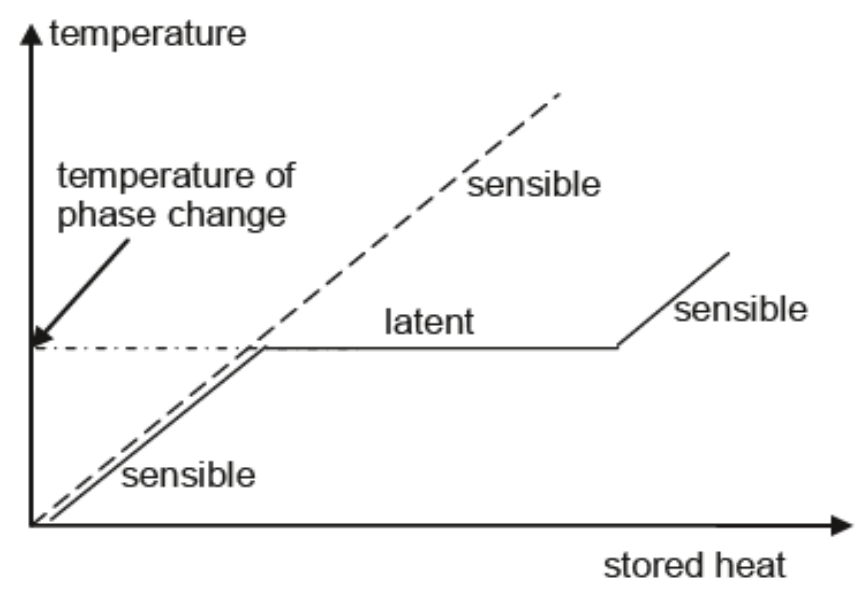

Figure 2: Working principle of sensible \& latent heat storage

A number of research studies have highlighted that latent heat storage systems utilizing a phase change material (PCM) are perhaps the most effective heat storage technique as they provide a very high energy density during the melting and solidification processes compared to the conventional sensible heat energy storage systems. This means that a latent heat storage system using a PCM requires a much smaller volume of materials to store a certain amount of energy,(Al-Maghalseh and Mahkamov, 2018).

\section{HEART toolkit descriptions}

HEART stands for Holistic Energy and Architectural Retrofit Toolkit. The project follows the goals of the European Union to reduce the consumption of primary resources by $80 \%$ by the end of 2050 , which can be achieved with almost zero-energy buildings. Therefore, the project foresees the creation of a software toolkit that will enable a comprehensive energy and architectural renovation of buildings. The synoptic outline of such a smart almost zero-energy building are presented in Figure 3, where all electric, thermal and information flows are presented.

Synoptic Outline

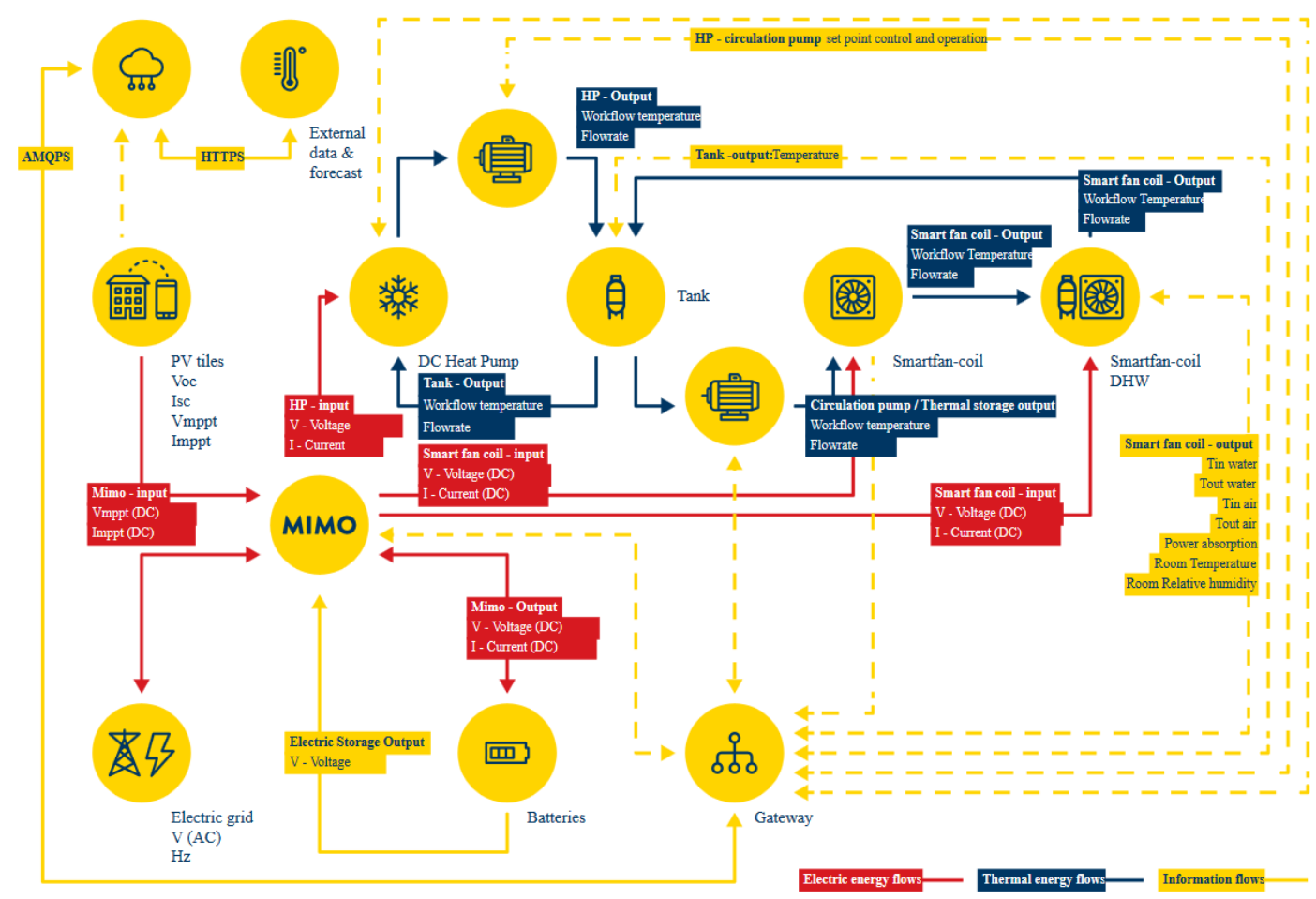

Figure 3: Concept of HEART toolkit, ("Heart EU Project website - grant agreement No. 768921," n.d.) 
The software toolkit will be used in all phases of the project, from conceptual design to management and maintenance of the building. HEART is a multifunctional retrofit toolkit that includes different components in building retrofit process such as: ICT (Information and Communication Technology), BEMS (Building Energy Management Systems), HVAC (Heating, Ventilation and Air Conditioning), BIPV (Building Integrate Photovoltaic) and Envelope Technologies which operate synergistically to transform an existing building into smart building.

The toolkit runs on cloud-based platform with computing power, concentrating managing and operational logic that supports decision-making in the planning phase of building energy retrofit and optimizes energy performance in the operational one.

The concept of HEART toolkit with included subcomponents and their connectivity in the system is presented in the Figure 4. Those subcomponents are under development within the consortium of HEART project and are listed below:

- Cloud-based DSS (Decision Support System) and BEMS (Building Energy Management System),

- Multifunctional prefabricated external thermal insulation in which wiring, pipes, vents and sensing options can be integrated,

- Universal PV tiles for pitched roofs, customized with respect to common roofing (for flat rooftops regular open racks systems would do),

- Multi-Input/Multi-Output power controller for interconnection optimization among production, storage and consumption devices,

- Hydronic air to water DC modular heat pump,

- Advanced hot/cold storage units for thermal energy storage of heat pump that runs on PV,

- Battery pack for PV electricity and power management (the only subcomponent not specifically developed in the project),

- DC smart fan-coils for heating/cooling of rooms (replacing existing radiators), (Koželj et al., 2018).

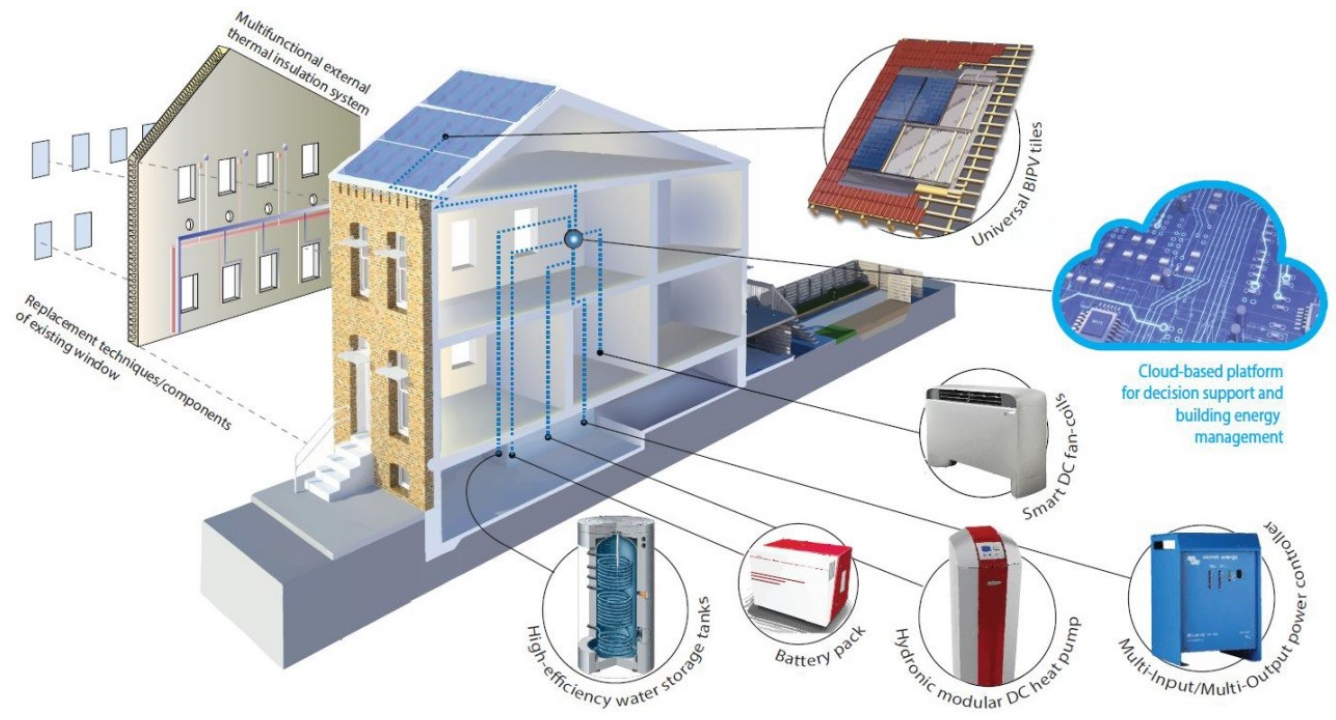

Figure 4: Concept of HEART toolkit, (Koželj et al., 2018)

\section{Experimental TES system with PCM}

The purpose of this experiment was to investigate improvement on increased energy density for thermal energy storage by integrating PCM modules in water storage tank. The influence of integrated modules on time of providing heat demand and the maximum heat output, has also been studied.

\subsection{Experimental system}

The experimental system was designed according to the standard VDI 2146 - PCM energy storage systems in building services (VEREIN_DEUTSCHER_INGENIEURE, 2016), which includes basic definitions and calculation procedures for evaluating thermal energy storage systems with PCMs. It defines measurements of heating and cooling of storage via internal heat exchanger or direct double port connections and measurements of thermal energy storage in standby. 


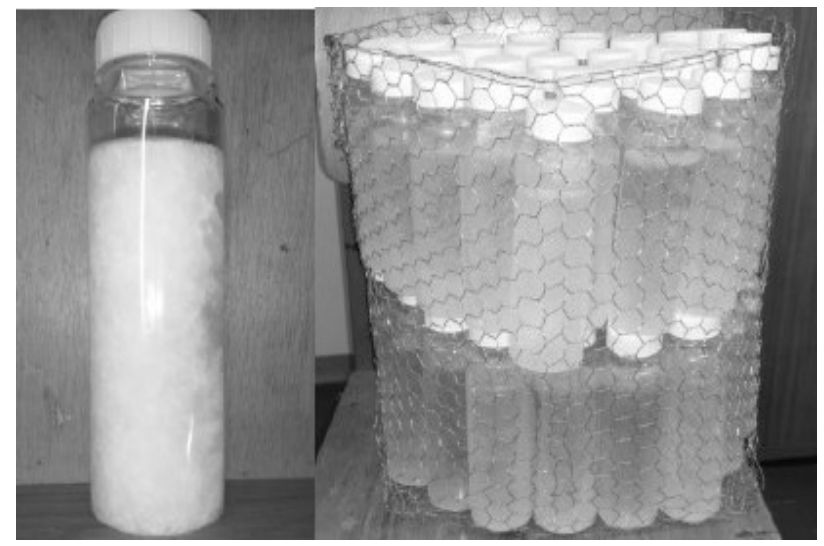

Figure 5: Cylindrical modules inserted into storage tank

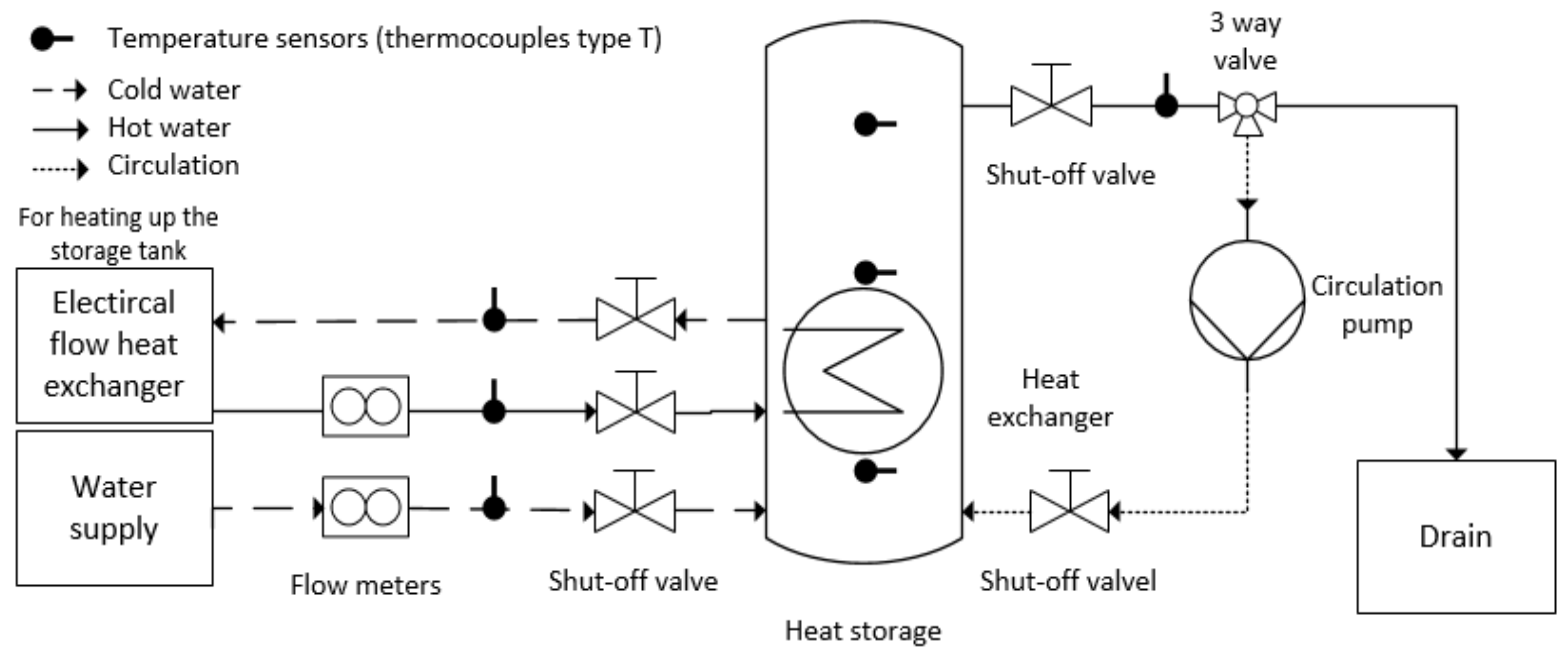

Figure 6: Scheme of the experimental setup

Figure 6 shows an experimental setup, where hydraulic connections and the locations of temperature sensors, shut-off valves and circulation pump can be seen.

The storage tank of volume $0,28 \mathrm{~m}^{3}$ was used. A large part of time has been dedicated to selection of the right shape of the modules. Important parameters in shape selection were available heat transfer area, which is crucial for the performance of the storage system, their sealing and mechanical resistance to prevent leakage and price of the modules. There are different forms in which PCMs can be brought into the storage tank, e.g. packs, panels, balls (spherical modules), cylindrical shape etc. According to the stated parameters, the cylindrical modules were chosen, as shown in Fig. 2. Each of them has a volume of $320 \mathrm{ml}$ and was filled with $250 \mathrm{ml}$ of PCM. This is due to thermal expansion of PCM when melted. PCM RT $28 \mathrm{HC}(\mathrm{GmbH}, 2016)$ was used which is paraffin with improved thermal capacitance of $250+/-7,5 \%$ and phase change temperature between $27{ }^{\circ} \mathrm{C}$ and $29^{\circ} \mathrm{C}$ with main peak at $28^{\circ} \mathrm{C}$. Then a metal mesh was installed into the storage tank, in which the cylindrical modules with PCM were stacked. A total of 172 modules were integrated with total volume of 43 I of PCM, which represent $15 \%$ of total volume of heat storage tank.

For the preparation of hot water, an electrical flow heat exchanger was used, which consists of two $2 \mathrm{~kW}$ electrical heaters. The mass flow rate was measured using flying start-stop method. Type $T$ thermocouples were used for measuring the temperature. In the experimental system there is also a circulation pump, which is used to establish a uniform temperature inside the storage tank.

\subsection{Measurements}

Two sets of measurements were performed, namely measurements of the sensible and measurements of the latent heat storage. The work focused on cooling the heat storage, as this is the most important part of operation of the heat storage. The sensible heat storage was heated up to an average temperature of 1 to 2 $\mathrm{K}$ higher than the desired temperature, which was $40{ }^{\circ} \mathrm{C}$. Then the circulation pump was turn on until a uniform temperature inside the heat storage tank was reached and the desired temperature was established. 
In the next phase, cold water was supplied via direct double port connection in the bottom of the storage tank, and consequently hot water was exiting on the top of the storage tank via direct double port connection.

In case of latent heat storage, a different approach was needed, since on the basis of a visual assessment it was not possible to assess whether the entire PCM was melted or not. The amount of energy required to complete the phase change was calculated. Accordingly, the initial water temperature in the storage was determined, so that entire PCM was melted and the heat storage stay heated to an average temperature of 1 to $2 \mathrm{~K}$ higher than desired temperature, which was $32{ }^{\circ} \mathrm{C}$. Then, the procedure was repeated as in the case of sensible heat storage to achieve uniform temperature inside the tank.

The temperature of supplied water was set to $5 \mathrm{~K}$ below phase change temperature. In this case this means $23{ }^{\circ} \mathrm{C}$, with maximum deviation of $0,33 \mathrm{~K}$. The water mass flow rate was set to $2 \mathrm{~kg} / \mathrm{min}$ with maximum deviation of $0,02 \mathrm{~kg} / \mathrm{min}$. The experiment was carried out under these conditions to the point where the temperature difference between the inlet and outlet water dropped below $0,5 \mathrm{~K}$.

However, it should be taken into account that with sensible heat storage you can achieve greater output thermal power compared to latent heat storage due to low thermal conductivity in case of paraffin, which should be taken into account when designing such system.

\section{Results and discussion}

Figure 5 and Figure 6 shows the temperature distribution across the heat storage tank. The proposed heating system requires a minimum inlet water temperature in the heating phase of $25^{\circ} \mathrm{C}$. This was also the point to which the time of covering the heat demand was measured. As it can be seen, the latent heat storage may, despite the lower initial temperature, provide a minimum temperature of $25^{\circ} \mathrm{C}$ for longer period of time. Latent heat storage can provide minimum outlet temperature of $25{ }^{\circ} \mathrm{C}$ for 300 min while sensible heat storage for $150 \mathrm{~min}$.

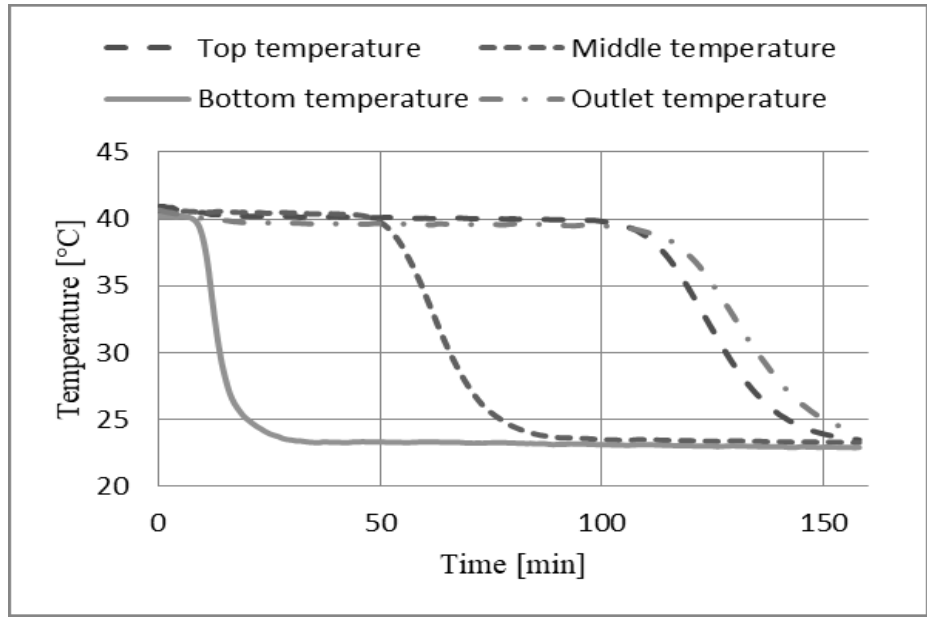

Figure 7: Temperature distribution in case of sensible heat storage.

Further on, the temperature of heat storage according to the stored energy was calculated, from Equations (3), (4) and (5), while the volume of the storage tank was assumed to be $1 \mathrm{~m}^{3}$. Equation (3) was used to calculate stored heat in the sensible heat storage. Equation (4) was used to calculate stored heat in the latent heat storage below the phase change temperature and Equation (5) was used for calculation of stored heat in latent heat storage above the phase change temperature. At the time when phase change took place constant temperature was assumed.

$$
\begin{aligned}
& Q_{s}=\rho_{w} \cdot V_{w} \cdot c_{p, w} \cdot\left(T_{s}-T_{f}\right) \\
& Q_{L}=\rho_{w} \cdot V_{w} \cdot c_{p, w} \cdot\left(T_{s}-T_{f}\right)+\rho_{P C M} \cdot V_{P C M} \cdot c_{p, P C M} \cdot\left(T_{s}-T_{f}\right) \\
& Q_{L}=\rho_{w} \cdot V_{w} \cdot c_{p, w} \cdot\left(T_{s}-T_{f}\right)+\rho_{P C M} \cdot V_{P C M} \cdot c_{p, P C M} \cdot\left(T_{s}-T_{f}\right)+\rho_{P C M} \cdot V_{P C M} \cdot h
\end{aligned}
$$




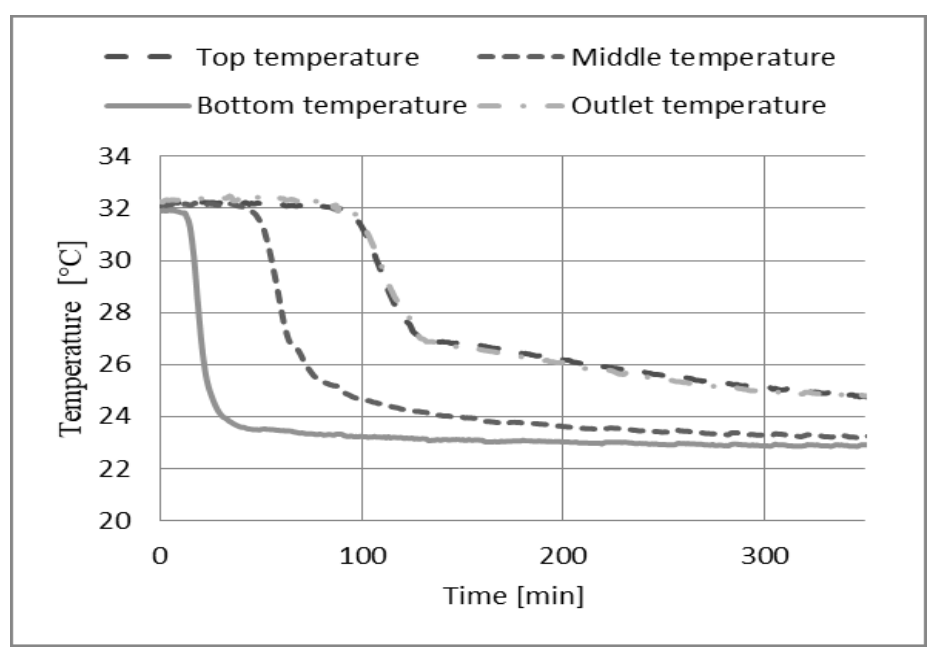

Figure 8: Temperature distribution in case of latent heat storage.

Equation (3), (4) and (5) consists of following parameters: heat (Q), density ( $\rho)$, volume (V), specific heat (c), temperature (T) and specific enthalpy (h). The subscript $w$ is for water, PCM is for phase change material, $s$ is for start and $f$ is for finish state.

Figure 9 shows dependence of the temperature of the heat storage fluid on the stored energy in volume of 1 $\mathrm{m}^{3}$ for sensible heat storage and latent heat storage at three different level of PCM filling. From results we see that the increase in the percentage of the PCM greatly lowers the temperature in the storage tank. However, because of the lower specific heat of the PCM compared to water, this advantage is reduced by increasing the temperature of the storage tank.

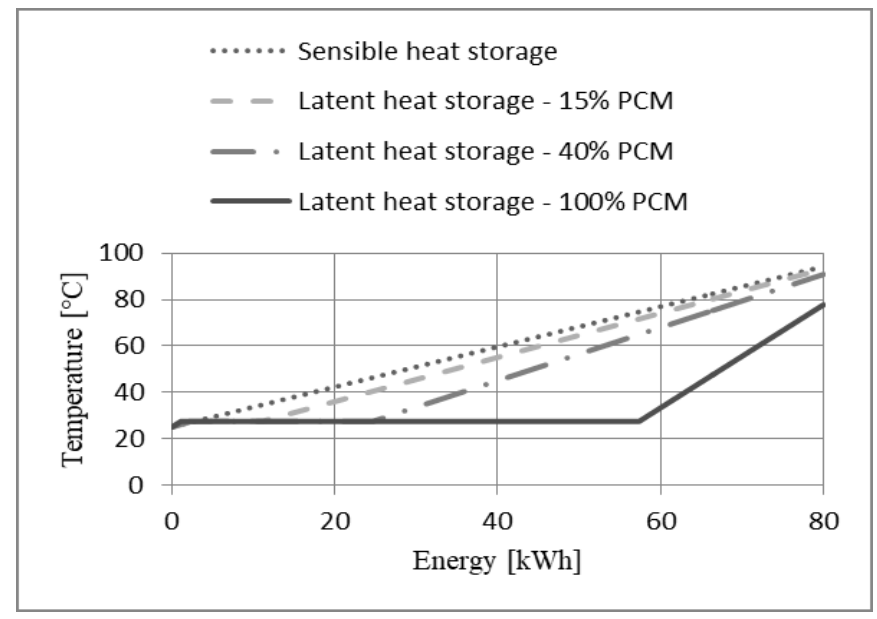

Figure 9: Temperature of storage tank according to stored energy.

Figures 10 and Figure 11 shows dependence of volume of the heat storage on stored energy (heat) at temperature difference $5 \mathrm{~K}$ and $25 \mathrm{~K}$, respectively. As expected, the volume of the storage tank is reduced by increasing the percentage of the PCM. This difference is reduced by increasing the temperature differences between the initial and final temperature when storing heat. This also indicates that heat storage with PCMs have great advantage at smaller temperature difference of operating system compared to sensible one. According to the results shown in Figures 7, 8, 9 and 10, one can decide between two options: by integrating modules with PCM, the temperature of storage can be greatly reduced and energy density of stored heat can be increased at the same volume of storage, or total volume of storage can be decreases and the same temperature is maintained compared to the sensible heat storage. 


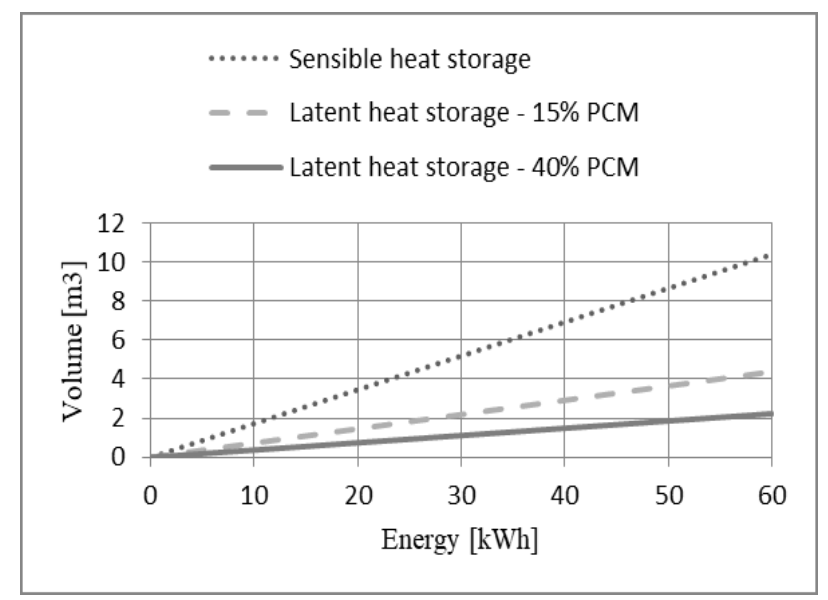

Figure 10: Volume of storage tank according to stored energy at temperature difference $5 \mathrm{~K}$.

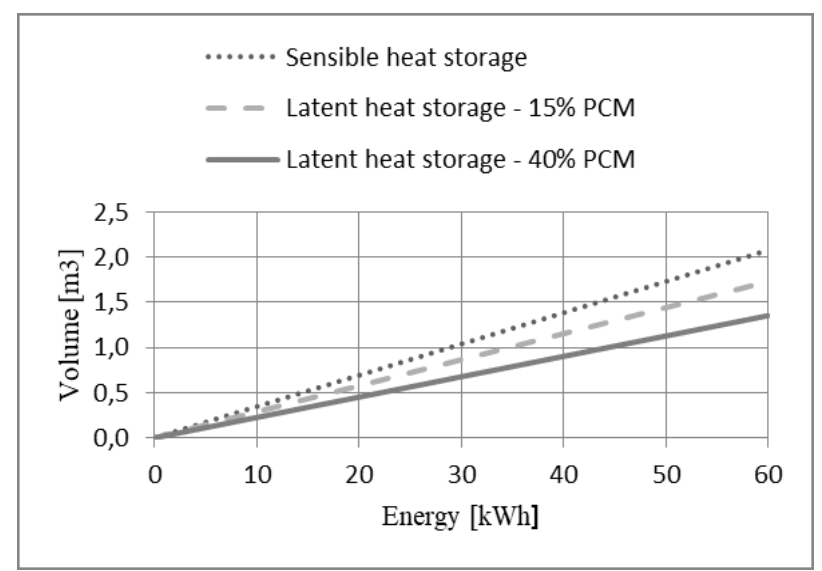

Figure 11: Volume of storage tank according to stored energy at temperature difference $25 \mathrm{~K}$.

\section{Conclusion}

This work presents the main advantages of the latent heat storage, which is one of the components in proposed system within the HEART EU project, that will play a big role in sustainable energy use and have a great potential for the use in residential buildings to achieve nearly zero energy buildings.

For implantation of latent (PCM) thermal storage system with high efficiency, it is important to have small temperature differences between the initial and final temperature when storing heat. This is also the main advantage of latent heat storage, storing of large amounts of heat within a narrow more constant temperature range compared with conventional sensible storage tank. A higher heat storage density can also mean a smaller system, compared with sensible storage, for storing heat, which is especially advantageous in case where we are dealing with a lack of space and it's also more sustainable. The advantages of using latent heat storage are reflected primarily in combinations with heat pumps, where more constant temperature conditions allow the operation of the heat pump in more stable conditions, which is reflected in achieving better efficiency of operation for the whole system in our case this could lead to more sustainable and nearly zero energy buildings in the future.

\section{Acknowledgments}

This experimental work was supported by European Union Research and Innovation programme Horizon 2020 grant agreement 768921 - HEART. 


\section{References}

Al-Maghalseh, M., Mahkamov, K., 2018. Methods of heat transfer intensification in PCM thermal storage systems: Review paper. Renew. Sustain. Energy Rev. doi:10.1016/j.rser.2018.04.064

Arkar, C., Medved, S., 2015. Optimization of latent heat storage in solar air heating system with vacuum tube air solar collector. Sol. Energy 111, 10-20. doi:10.1016/J.SOLENER.2014.10.013

Auzeby, M., Wei, S., Underwood, C., Chen, C., Ling, H., Pan, S., Ng, B., Tindall, J., Buswell, R., 2017. Using Phase Change Materials to Reduce Overheating Issues in UK Residential Buildings. Energy Procedia 105, 4072-4077. doi:10.1016/j.egypro.2017.03.861

D'Agostino, D., Mazzarella, L., 2019. What is a Nearly zero energy building? Overview, implementation and comparison of definitions. J. Build. Eng. 21, 200-212. doi:10.1016/J.JOBE.2018.10.019

European Commission, 2016. COMMUNICATION FROM THE COMMISSION TO THE EUROPEAN PARLIAMENT AND THE COUNCIL - The Road from Paris. doi:10.1360/zd-2013-43-6-1064

Fiorentini, M., Cooper, P., Ma, Z., 2015. Development and optimization of an innovative HVAC system with integrated PVT and PCM thermal storage for a net-zero energy retrofitted house. Energy Build. 94, $21-$ 32. doi:10.1016/J.ENBUILD.2015.02.018

Gil, A., Medrano, M., Martorell, I., Lázaro, A., Dolado, P., Zalba, B., Cabeza, L.F., 2010. State of the art on high temperature thermal energy storage for power generation. Part 1-Concepts, materials and modellization. Renew. Sustain. Energy Rev. 14, 31-55. doi:10.1016/j.rser.2009.07.035

$\mathrm{GmbH}$, R.T., 2016. GmbH, RUBITHERM® Technologies: Data Sheet RT28HC PCM.

Good, C., Andresen, I., Hestnes, A.G., 2015. Solar energy for net zero energy buildings - A comparison between solar thermal, PV and photovoltaic-thermal (PV/T) systems. Sol. Energy 122, 986-996. doi:10.1016/j.solener.2015.10.013

Heart EU Project website - grant agreement No. 768921 [WWW Document], n.d. URL https://heartproject.eu/ (accessed 12.13.18).

J. M. Schultz, Sole, C., Cabeza, L., Bony, J., Heinz, A., Streicher, W., 2007. Laboratory Prototypes of PCM Storage Units, TASK 32. Rep. C3 Subtask C within IEA Sol. Heat. Cool. Program. task 32.

Koželj, R., Stropnik, R., Zavrl, E., Stritih, U., 2018. Improved thermal energy storage with PCM - An important part of EU project concept Holistic Energy and Architectural Retrofit Toolkit ( HEART ). IEEP.

Kurnitski, J., 2013. Technical definition for nearly zero energy buildings - Active House Alliance. J. Fed. Eur. Heating, Vent. Air Cond. Assoc. 50, 22-28.

Kurnitski, J., Allard, F., Braham, D., Goeders, G., Heiselberg, P., Jagemar, L., Kosonen, R., Lebrun, J., Mazzarella, L., Railio, J., Seppanen, O., Schmidt, M., Virta, M., 2012. How to define nearly net zero energy buildings nZEB. REHVA J. 6-12.

MEHLING, H., CABEZA, L.F., NOGUÉS, M., ROCA, J., ILLA, J., HIEBLER, S., 2003. PCM-module to improve hot water heat stores with stratification : first tests in a complete solar system. Futur. 2003.

Nchelatebe, D., Haghighat, F., 2013. Thermal energy storage with phase change material - A state-of-the art review. Sustain. Cities Soc. 10, 87-100. doi:10.1016/j.scs.2013.05.007

Sarbu, I., Sebarchievici, C., 2018. A comprehensive review of thermal energy storage. Sustain. 10. doi:10.3390/su10010191

VEREIN_DEUTSCHER_INGENIEURE, 2016. VDI 2164 - PCM energy storage systems in building services. 